\title{
Considerations on the Evaluation and Management of Volumetric Surface Defects on Pipelines Using 3D Scanning and Finite Element Analysis
}

\author{
IONUT LAMBRESCU*, ALIN DINITA, MIHAIL MINESCU \\ Petroleum - Gas University of Ploiesti, 39 Bucureşti Bvd., 100680, Ploiesti, Romania
}

\begin{abstract}
The paper proposes an original approach in the evaluation of the Volumetric Surface Defects (VSD) appearing in pipelines. The methodology we propose consists in performing, in the first phase, a superficial polishing (molding) of the VSD, such as the micro-cracks are eliminated. The second step implies 3D scanning of the molded VSD. The third step implies a comparative evaluation, using the Finite Element Analysis, of the pipeline with the polished VSD, and rectangular shaped machined VSDs. The comparative analysis will allow choosing the best scenario, both in terms of pipeline strength and economic efficiency (expressed in volume of the removed material).
\end{abstract}

Keywords: Pipeline, Defect, Assessment, 3D scanning

\section{Introduction}

Pipelines are frequently used for the transmission of oil, natural gas, liquid petroleum products, water etc. The most important factors affecting the integrity of pipelines are the corrosion and erosion processes that may generate local metal loss defects (Volumetric Surface Defects - VSD). As it is known [1-5], the residual mechanical strength and the operational safety of the steel pipelines is mainly determined by the following categories of factors: factors regarding the aggressiveness of the gases/fluids transported; factors regarding the quality of the steel from which the pipes are manufactured; factors regarding the constructive conception of the pipes and the technologies of pipe manufacture; factors regarding the working regime for gas/fluid transportation through pipelines.

In this context, it follows that the strategy to be adopted in order to establish the residual load carrying capacity and to develop the maintenance programs for any pipeline must include the following steps: A. determining the technical state of the pipeline (through periodic inspections); B. establishing the mechanical characteristics of resistance and tenacity of the material of the pipes; $\mathrm{C}$. estimation of the residual (remaining) mechanical strength of the pipeline; D. scheduling maintenance works and establishing the appropriate technologies for carrying out these works.

If on the surfaces of the pipes there are local defects caused by corrosion, the effects of diminishing the bearing capacity of the pipes, determined by the presence of these defects, are appreciated considering that each of these defects has three characteristic dimensions: the maximum depth $d$, the length (the extension in the direction of the longitudinal axis) of the pipe $L$ and width (extension in the circumferential direction) $C$. The exact determination of these characteristic geometric dimensions of VSD type defects is a delicate problem, the accuracy of these measurements affecting the decisions regarding the application of the different methods of evaluation and estimation of the carrying capacity.

The present paper proposes a new approach concerning the evaluation and management of VSDs, using 3D scanning and a subsequent Finite Element Analysis.

As mentioned above, when one deals with a VSD, the general approach is to machine the affected area, usually producing a rounded corners rectangle, with a depth such as to equal the maximum depth of the VSD (in general, the machined rectangle having edges parallel to the pipe axis), then using a reparation kit comprising a filler and a wrap to be applied around the pipe in the VSD area. 
https://doi.org/10.37358/RC.20.4.8039The role of the machining is to eliminate the micro defects that could favor the development of cracks capable to evolve into failure of the pipeline.

In the paper one proposes a different approach, that can pe described by the diagram from figure 1 .

Basically, what we wanted was to find the best choice in managing the VSD in terms of what machining strategy to use in order to get a safe repaired VSD with a minimum machined volume of material.

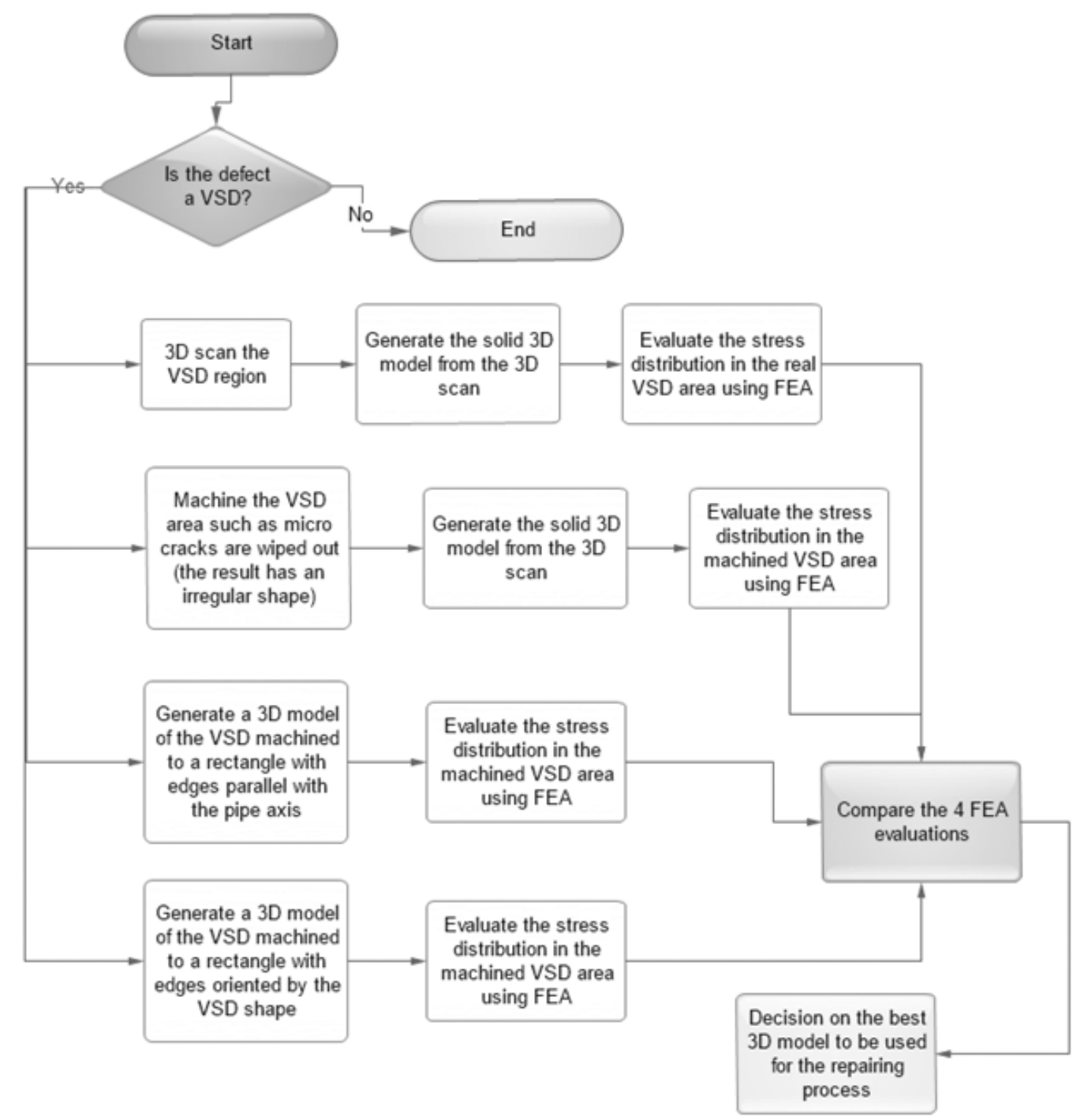

Figure 1. Work flow for the evaluation process

\section{Materials and methods}

A pipeline section (exterior diameter of $76.1 \mathrm{~mm}$ and wall thickness of $3.2 \mathrm{~mm}$ ) with an anomaly has been 3D scanned using an HP 3D Structured Light Scanner Pro 3. Figure 2 presents the scanning process along with the result of the process.

A solid 3D model of the pipeline with VSD has been obtained using reverse engineering techniques. One mention that the very small irregularities obtained after the 3D scanning have been neglected so apart from the VSD itself, the exterior face of the pipeline is considered perfectly cylindrical. 


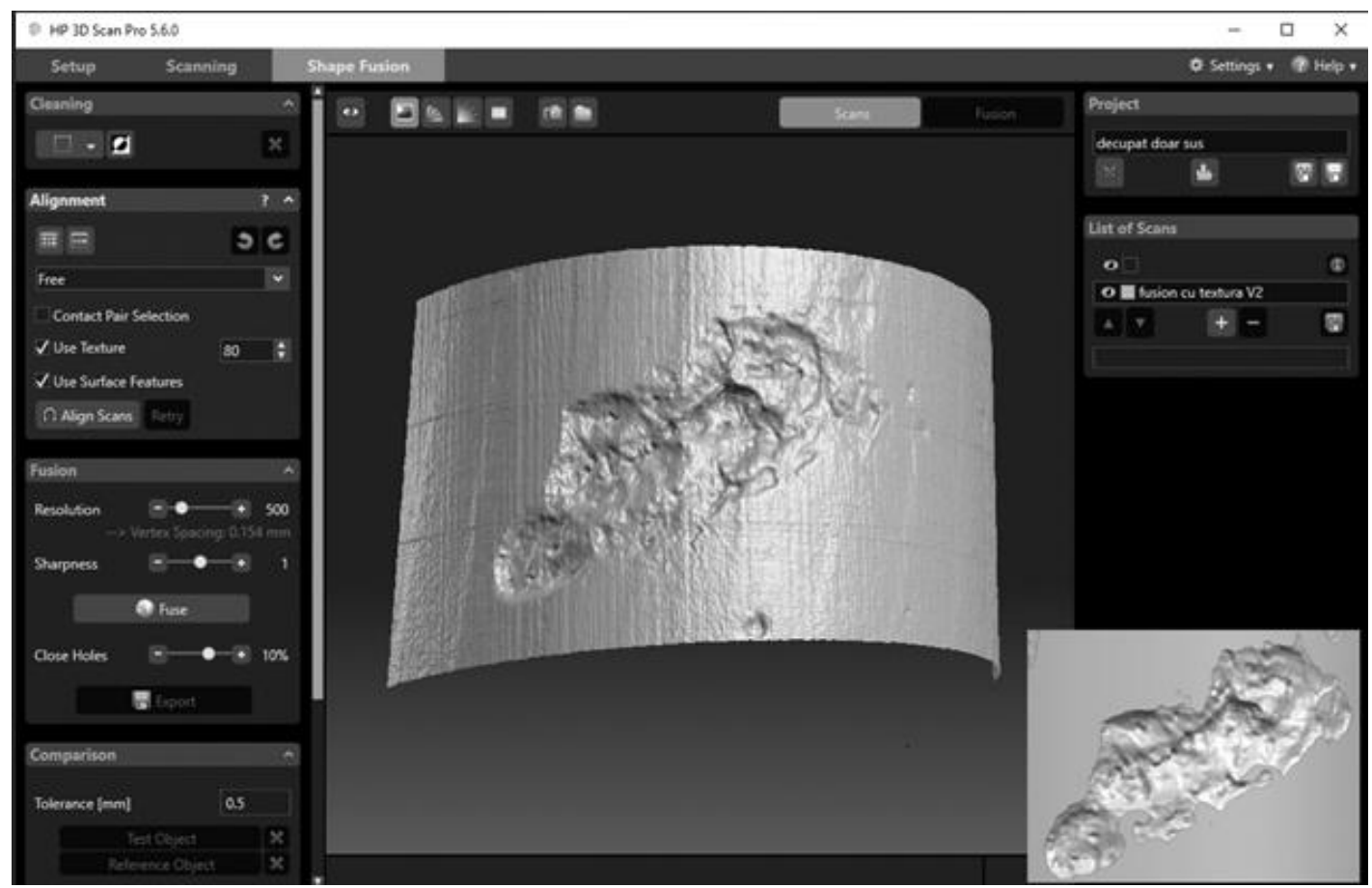

Figure 2. Scanning process and result

The VSD area has bee machined using an abrasive head such as one obtained a smoother VSD. The abrasive tool and the result of the machining process are presented in Figure 3. The resulting pipeline segment has been 3D scanned. The resulting VSD, integrated in a solid 3D model is presented in figure 4. Measuring the real and the molded VSD, one reached the values presented in Table 1.

Table 1. Real vs molded VSD important dimensions [mm]

\begin{tabular}{ccc}
\hline Property & Real VSD & Molded VSD \\
\hline VSD depth & 2.29 & 2.38 \\
\hline VSD minimum wall thickness & 0.91 & 0.82 \\
\hline$\%$ of VSD depth from wall thickness & $71.5 \%$ & $74 \%$ \\
\hline
\end{tabular}

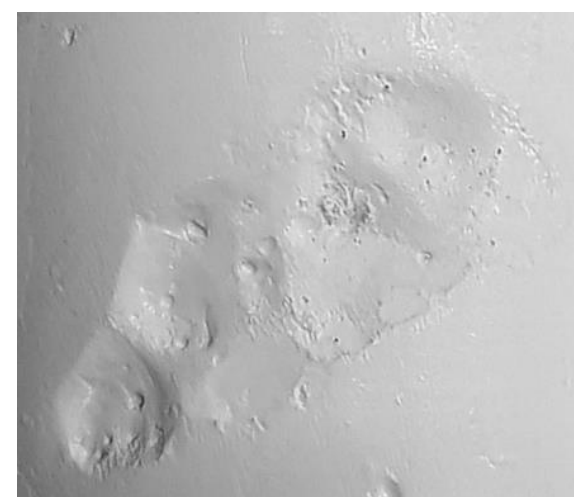

a. Molded VSD

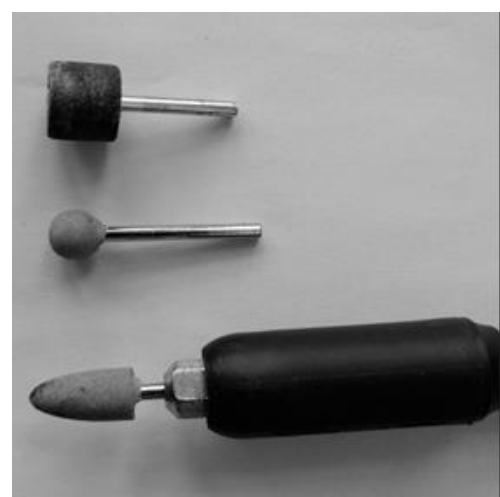

b. Tools for molding

Figure 3. Tool and result of the machining/polishing process 


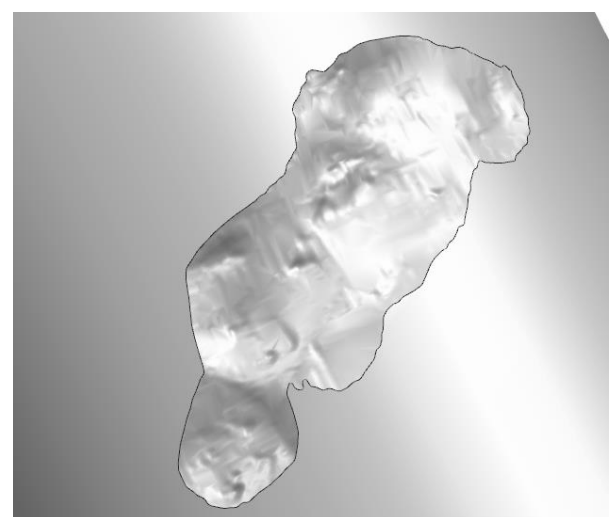

Figure 4. Molded VSD scanned and integrated into a solid 3D model

\section{Finite Element Analysis}

The Finite Element Analysis [6 - 10] performed for the real and molded VSD pipe were carried out (using the ANSYS package) considering the following conditions:

- Pipe material: L290MB;

- Working pressure: $20 \mathrm{bar}\left(2 \mathrm{~N} / \mathrm{mm}^{2}=2 \mathrm{MPa}\right)$;

- Considered pipe segment fixed at both ends;

- $\quad$ Pipe segment length: $534 \mathrm{~mm}$;

- Average tetrahedral element size for the pipe body: $1.6 \mathrm{~mm}$;

- Average tetrahedral element size in the VSD vicinity: $0.5 \mathrm{~mm}$;

- Average tetrahedral element size on the VSD surface: $0.15 \mathrm{~mm}$.

Finite Element Analysis were also performed for the pipe with rectangle shape machined VSDs. For the rectangle shaped, the VSDs depth corresponds to the maximum depth of the molded one $(2.38 \mathrm{~mm})$. Figure 5 presents the two rectangle machined VSD analyzed.

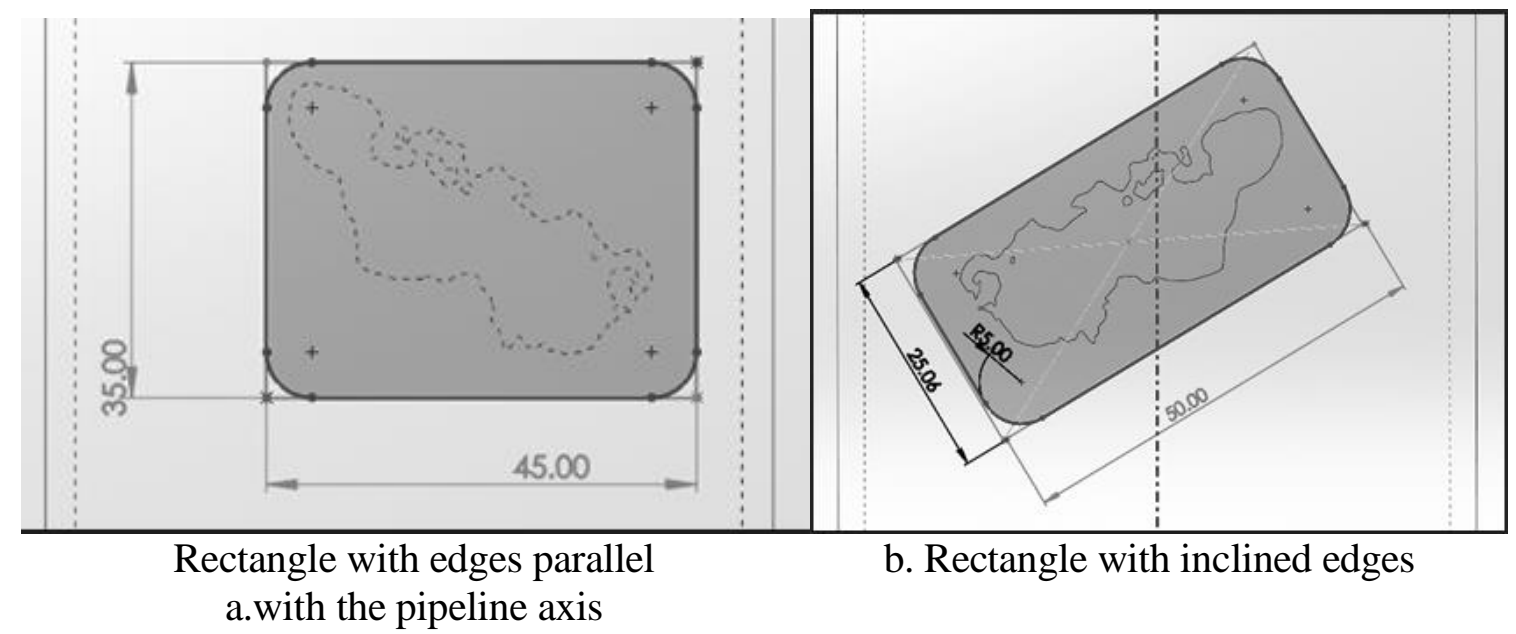

Figure 5. Rectangle shaped machined VSDs

\section{Results and discussions}

For the four considered cases, static structural analysis has been performed using ANSYS Workbench.

Figure 6 presents the Von Mises stress distributions for the four cases. 

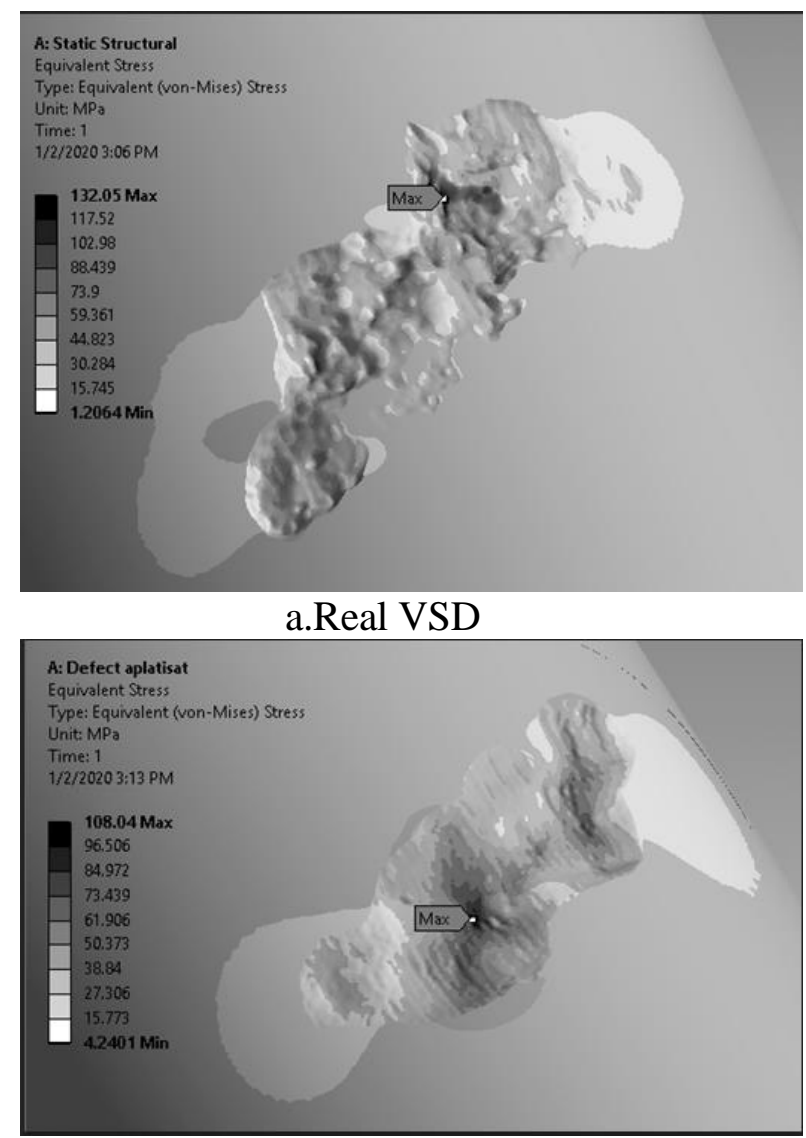

b.Molded VSD

Figure 6. Von Mises stress distributions for the four cases

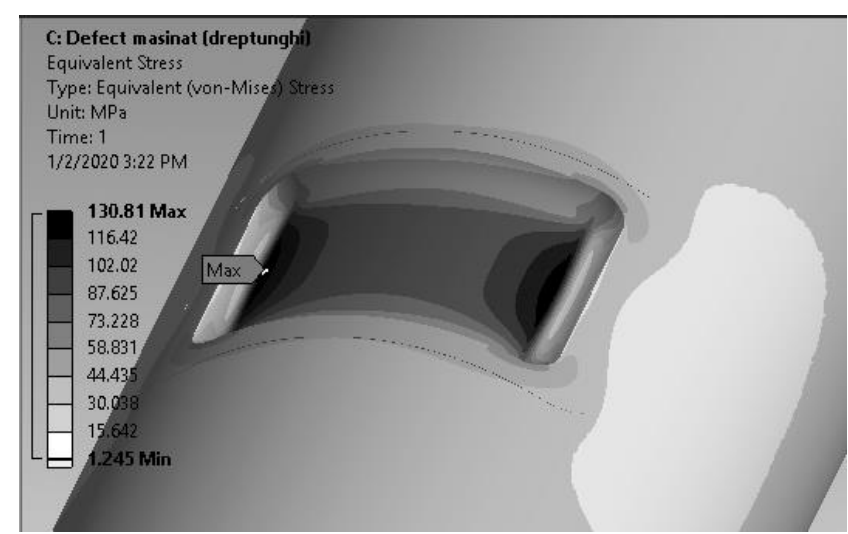

c.Rectangle machined VSD (edges parallel with pipeline axis)

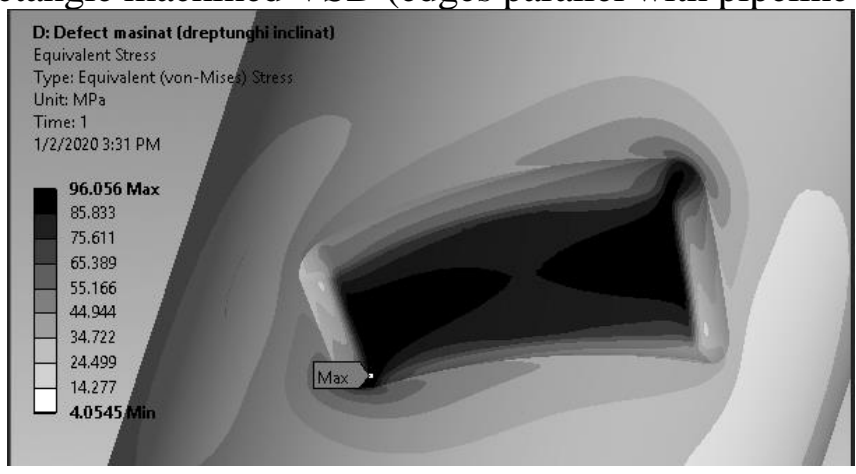

d.Rectangle machined VSD

Figure 6. Von Mises stress distributions for the four cases (continuation) 
The results are synthetically presented in Table 2. The second column presents the maximal Von Mises equivalent stress for the four considered cases. The third column contains the volume of the removed material (always compared with the real VSD), while the last column shows this volume as a percentage of the volume of the real VSD.

Table 2. Von Mises equivalent stress and material removed

\begin{tabular}{lccc}
\hline VSD type & $\begin{array}{c}\text { Von Mises stress } \\
{[\mathbf{m a x} \text { value] [MPa] }}\end{array}$ & $\begin{array}{c}\text { Volume of removed material } \\
{\left[\mathbf{m m}^{\mathbf{3}}\right]}\end{array}$ & $\begin{array}{c}\text { Volume of removed material } \\
{[\% \text { of real VSD] }}\end{array}$ \\
\hline Real & 132.05 & $297.30^{1}$ & $100.0 \%$ \\
\hline Molded & 108.04 & $165.08^{2}$ & $55.5 \%$ \\
\hline Rectangle & 130.81 & $2963.70^{3}$ & $996.9 \%$ \\
\hline Inclined rectangle & 96.06 & $2197.70^{4}$ & $739.2 \%$ \\
\hline
\end{tabular}

In order to better evaluate the significance of the results, Figure 7 presents the Von Mises equivalent stress as bottom capped iso surfaces. The inferior limit has been set at $75 \%$ of the maximal value (for the Von Mises stress).

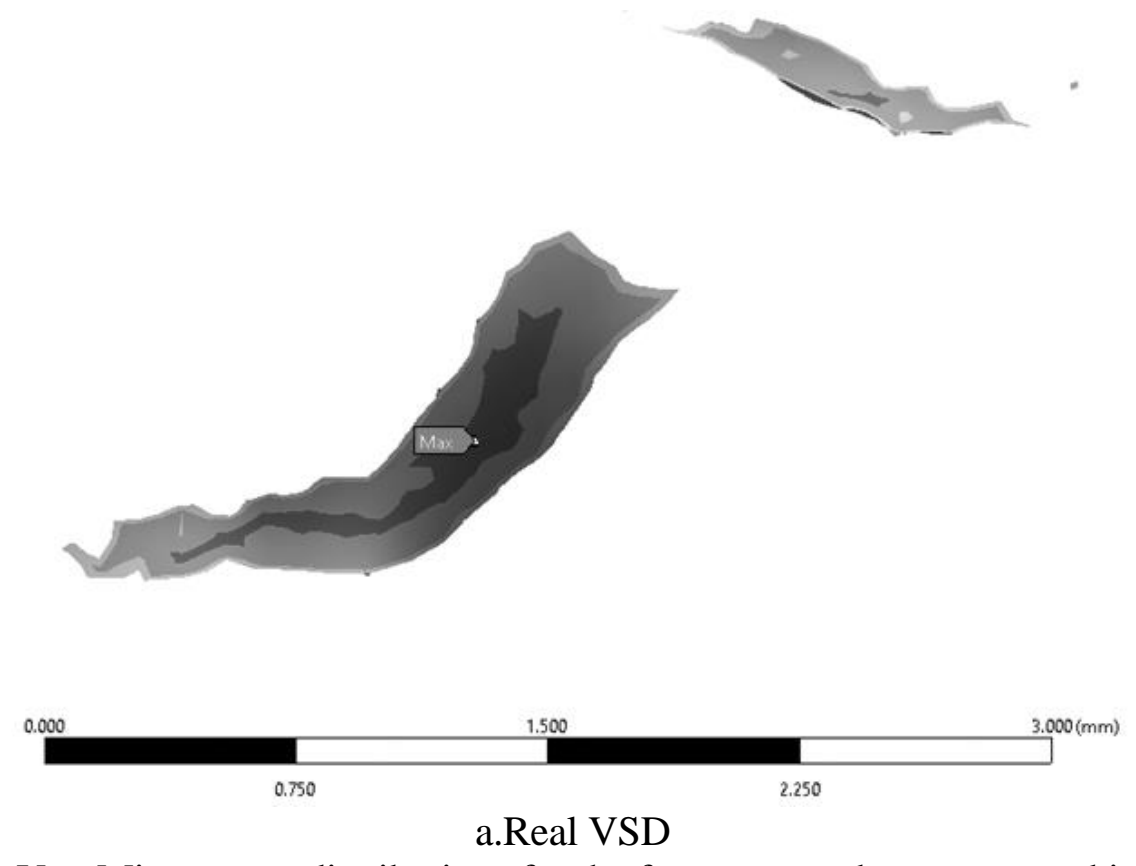

Figure 7. Von Mises stress distributions for the four cases as bottom capped iso surfaces

\footnotetext{
${ }^{1}$ Volume of the material missing due to corrosion or other causes

${ }^{2}$ Volume of the molded material

${ }^{3}$ Machined volume compared with the pipeline with real VSD

${ }^{4}$ Machined volume compared with the pipeline with real VSD
} 

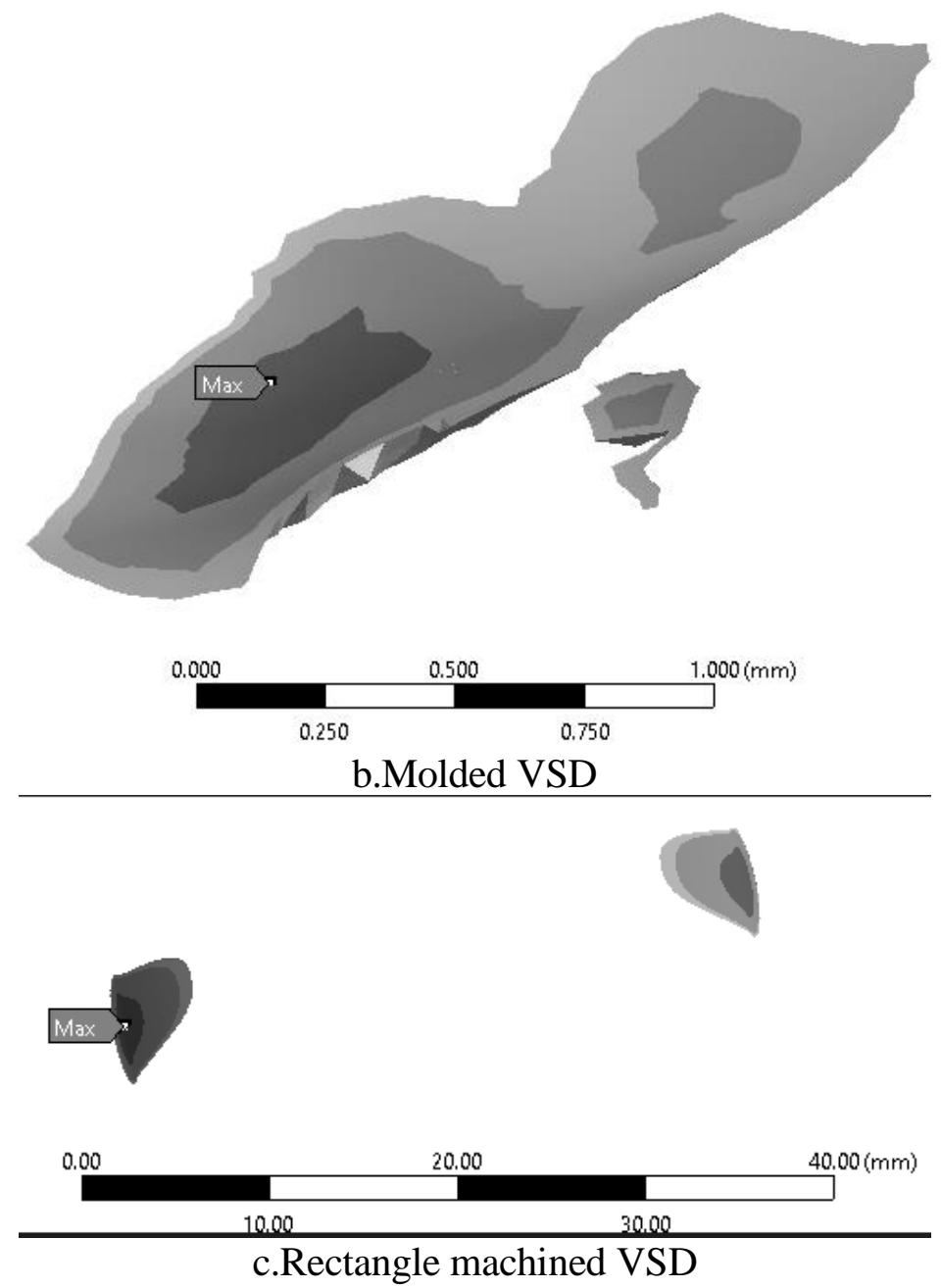

Figure 7. Von Mises stress distributions for the four cases as bottom capped iso surfaces (continuation)

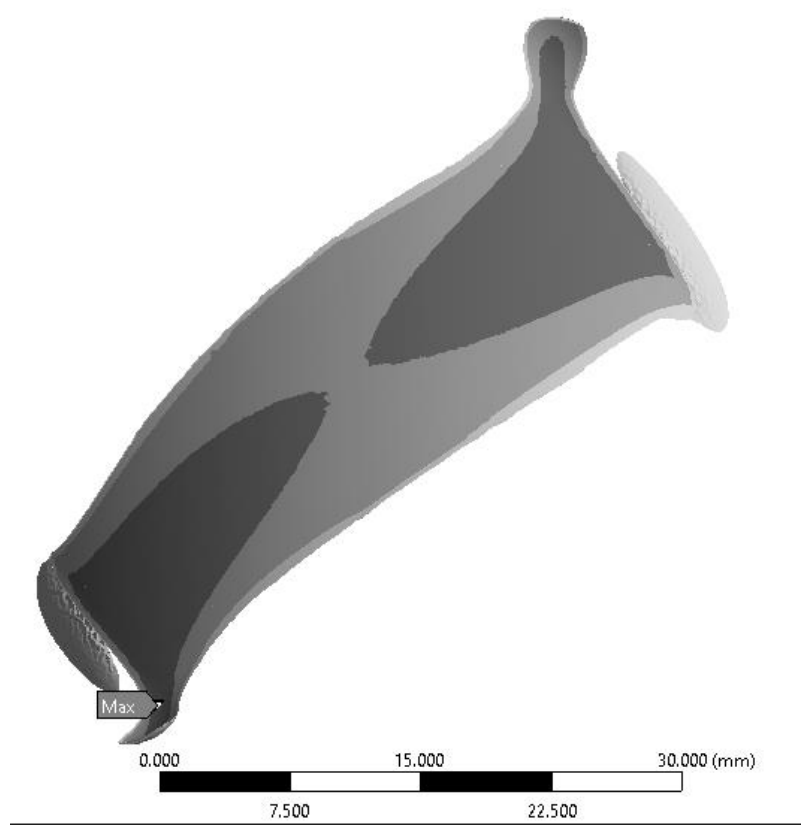

d.Inclined rectangle machined VSD

Figure 7. Von Mises stress distributions for the four cases as bottom capped iso surfaces (continuation) 
One mentions that the finite element results obtained in ANSYS were in good accordance (3-5\% maximal differences) with the ones obtained in Siemens NX.

\section{VSD evaluation with ANSI / ASME B31 G method}

In its original form [11,12], the procedure is based on comparing the length of the VSD with a certain depth $d$ from the pipe wall with outer diameter $D$ and the thickness of the wall $t$, with a maximum allowed length calculated with the relation:

with

$$
B=\sqrt{\left(\frac{d / t}{1,1 d / t-0,15}\right)^{2}-1} \leq 4
$$

The limit length values $L$ is given in the respective norm and table according to the outer diameter of the pipe and the thickness of the wall. If the measured length $L_{m}$ is $L_{m} \leq L$, or $d \leq 0.1 t$ the VSD is considered "permissible imperfection" under the given conditions, and no repair work should be performed. If $d \geq 0,1 t$ and $L_{m}>L$ then the anomaly is a defect and the effects it has on the safe operation of the pipe must be investigated.

For this, the ANSI / ASME B31 G method provides for the determination of the safe operating pressure $p$ ' in the presence of the defect, as follows:

$$
\begin{gathered}
A=0,893 \frac{L_{m}}{\sqrt{D t}} \\
\text { - } \quad \text { if } A \leq 4, \\
p=1,1 p\left[\frac{1-\frac{2}{3}\left(\frac{d}{t}\right)}{\left.1-\frac{2}{3}\left(\frac{d}{t}\right)\left(\frac{1}{\sqrt{A^{2}+1}}\right)\right],},\right.
\end{gathered}
$$

- $\quad$ and if $A>4$,

$$
p^{`}=1,1 p\left(1-\frac{d}{t}\right)
$$

where $\mathrm{p}$ is the maximum allowable pipe design pressure:

$$
p=\frac{2 R_{t 0,5} t F T J}{D}
$$

in which: $R_{t 0,5}$ yield strength; $t$ - wall thickness; $D$ - outer diameter; $F$ - design factor; $T$ - temperature factor; $J$ - pipe joint factor.

The safe operating pressure in the presence of $V S D$ is compared with the maximum operating pressure under the given conditions $p_{o}$ :

- if $p^{`}>p_{o}$, the anomaly is subjected to monitoring and repaired before it reaches dimensions for which calculated with relation (5) or relation (6) becomes $p^{`}<p_{o}$;

- if $p^{`}<p_{o}$, the anomaly is in UNSAFE DOMAIN and maintenance must be applied and the operating pressure reduced to a value $p_{o} \leq p$.

The results of the VSD evaluation analyzed in the previous chapter (following the steps from equation 1 to 6 of the procedure) are presented in the figure 8 . 


\section{DATA INPUT}

\begin{tabular}{|l|r|l|}
\hline Outer Pipe Diameter (De) & 76.1 & $\mathrm{~mm}$ \\
\hline Wall Thickness (t) & 3.2 & $\mathrm{~mm}$ \\
\hline Pipe Strength Rp & 290 & $\mathrm{~N} / \mathrm{mm} 2$ \\
\hline Operating Pressure (MOP) & 20 & $\mathrm{bar}$ \\
\hline Design Factor (F) & 0.72 & \\
\hline Temperature Factor (T) & 1 & \\
\hline Pipe Joint Factor (J) & 1 & \\
\hline VSD Depth & 2.38 & $\mathrm{~mm}$ \\
\hline VSD Length & 35.4 & $\mathrm{~mm}$ \\
\hline Corossion Speed & 1 & $\mathrm{~mm} / \mathrm{an}$ \\
\hline
\end{tabular}

Note: $20 \mathrm{bar}=2 \mathrm{~N} / \mathrm{mm}^{2}=2 \mathrm{MPa}$.

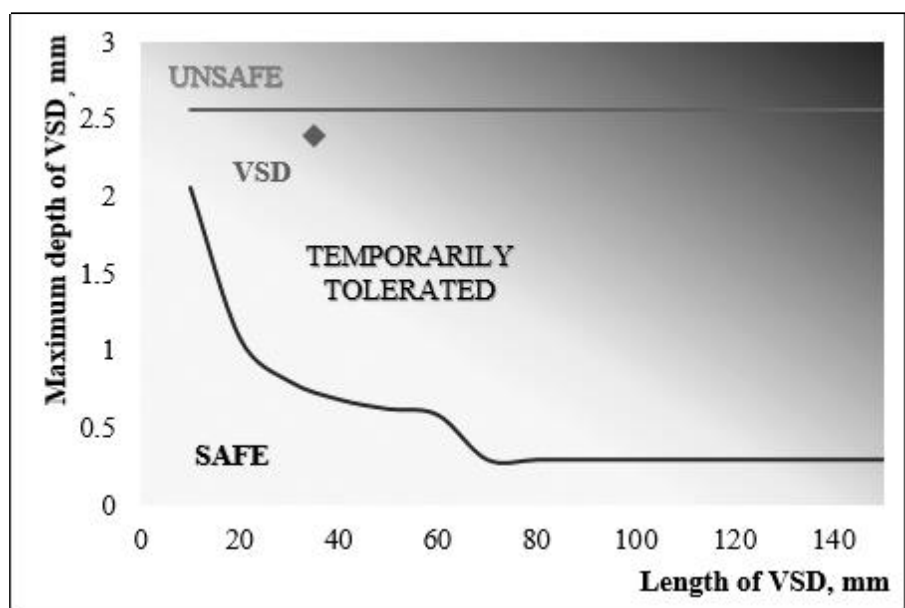

Figure 9. VSD analysis using the procedure from ANSI / ASME B31 G

\section{Conclusions}

The comparative analysis of the four cases, allows us to formulate the following conclusions:

- The stress distribution for the real VSD is obtained just as a reference for the other three cases taken in consideration in this paper;

- The Von Mises maximal equivalent stress reach maximum values for the real VSD and the rectangular (with edges parallel with the pipeline axis) machined VSD: $132.05 \mathrm{MPa}, 130.81 \mathrm{MPa}$ respectively;

- The Von Mises maximal equivalent stress reach the minimal values for the molded VSD and the inclined machined rectangle VSD: 108.04 MPa, 96.06 MPa respectively;

- From the point of view of the extension of the areas where the Von Mises equivalent stress surpasses $75 \%$ of the maximal (Von Mises) value, the molded VSD case seems to be the most favorable, since the overall dimensions of this area are in the range of $1.5 \mathrm{~mm}$. The less favorable case, from this point of view is the one of the inclined machined rectangle, with an area in the range of 40 $\mathrm{mm}$;

- Another criterion to be considered is the volume of the removed material (molded or machined). From this point of view, the molded VSD case is by far the most favorable.

Taking all of the above into consideration, one can state that, using the 3D scan approach it is possible to consider as a strategy for the VSD management to accept the molded VSD as a working version to replace the rectangular machined VSDs. This approach will produce a more favorable stress 
distribution (in terms of intensity and spread area), along with a significantly reduced removed material volume. This last advantage becomes even more important in the case of large diameter pipelines.

\section{References}

2.DUMITRESCU, A., ZECHERU, GHE., DINITA, A., "Characterization of Volumetric Surface Defects." Non-destructive Testing and Repair of Pipelines. Springer International Publishing AG, Cham, Switzerland, 2018, p. 117-135.

2.YU, C., QIU, B., HU, J. et al. Mechanical Behavior and Evaluation of Dented Pipe Caused by Cylindrical Indenter, Journal of Failure Analysis and Prevention, 2019, p. 519-535; doi:10.1007/s11668-019-00629-7.

3.KYU JUNGYEOM, YOUNG-KWANGLEE, KYU HWANOH, WOO SIKKIM, Integrity assessment of a corroded API X70 pipe with a single defect by burst pressure analysis, Engineering Failure Analysis, Volume 57, November 2015, p. 553-561.

4.CHANGQING G., WENXING Z., First-order reliability method-based system reliability analyses of corroding pipelines considering multiple defects and failure modes, Structure and Infrastructure Engineering, 2017, 13 (11), p. 1451-1461.

5.VILKYS T., RUDZINSKAS V., PRENTKOVSKIS O., TRETJAKOVAS J., VIŠNIAKOV N., MARUSCHAK P., Evaluation of Failure Pressure for Gas Pipelines with Combined Defects, Metals, 2018, 8(5), p. 346.

6.STOLARSKI T., NAKASONE Y., YOSHIMOTO S.. Engineering Analysis with ANSYS SOFTWARE, Elsevier BH, Oxford, 2006.

7.ZIENKIEWICZ, O. C., TAYLOR, R. L. - Finite Element Method for Solid and Structural Mechanics, Sixth Edition, Elsevier BH, Oxford, UK, 2006.

8.CHAN, WAI - FAN, LUI ERIC N., Handbook of Structural Engineering, Second Edition, CRC Press, New York, USA, 2005.

9.MADENCI E., GUVEN I., The Finite Element Method and Applications in Engineering Using ANSYS®, Springer USA, 2015

10.ZECHERU GH., YUKHUMETS P., DRĂGHICI GH., DUMITRESCU A., Methods for determining the remaining strength factor of pipelines with volumetric surface defects, Rev. Chim., 66 , (5), 2015, $710-717$.

11.***B31G - 2012. Manual for Determining the Remaining Strength of Corroded Pipelines (Code for Pressure Piping), American Society of Mechanical Engineers (ASME), October 2012..

12.FILIP M. Şt., Contribuţii privind evaluarea stării de degradare a reţelelor urbane de distribuţie a gazelor naturale, Teză de doctorat, Universitatea Petrol - Gaze din Ploieşti, 2016.

$\overline{\text { Manuscript received : 20.01.2020 }}$ 
